\title{
PRIMARY SENSORY NEUROPATHY WITH MUSGULAR CHANGES ASSOCIATED WITH CARCINOMA
}

\author{
BY \\ D. DENNY-BROWN
}

From the National Hospital for Nervous Diseases, Queen Square, London, the Neurological Unit, Boston City Hospital, and the Department of Neurology, Harvard Medical School, Boston, Massachusetts

(RECEIVED DECEMBER 12, 1947)

Among the many clinical forms of polyneuritis, one that affects sensory function alone is sufficiently unusual to attract more than passing attention. In milder forms of infective polyneuritis and in unusual post-diphtheritic cases the clinical phenomena may be predominantly sensory, but evidence of muscular weakness and wasting, particularly in proximal muscle groups, can usually be demonstrated. The so-called diabetic ataxia and alcoholic tabes are also not clear-cut sensory disorders. Herpetic zona is not only confined to a single or related group of nerve roots, but is also regularly accompanied by a motor component, an anterior poliomyelitis, which is more evident if the involved segments supply the musculature of a limb. The syndrome presented below could be classed among the ataxias, presenting as it does a severe disorganization of movement. From the first the severity of loss of general sensation, beginning at the periphery of the limbs, advancing to include the trunk, and in one case the face, differentiated the clinical picture from that of tabes dorsalis. The coexistence of "myositis" was not suspected during life.

Both patients* were observed in 1939, and though the pathological material has been preserved, the part of the clinical record of Case 2 dealing with the last two months of the patient's illness was lost during the war years by the hospital where he was admitted. Sufficient, however, remains from myi personal record of the earlier part of his illness to indicate the identity of the process in the two patients.

\section{Case Histories}

Case 1.-The first patient was demonstrated at a clinical meeting of the Royal Society of Medicine on

\footnotetext{
* The two cases presented here are included with one other in a * The two cases presented here are included with one other in a
paper by $\mathrm{R}$. Wyburn-Mason on " Bronchial Carcinoma presenting as Polyneuritis," in the Lancet of Feb. 7, 1948, p. 203, which has appeared since the present paper went to press. The detailed pathological analysis reported here does not support the theory of "refiex" production of peripheral neuritic symptoms (in analogy with pulmonary osteo-arthropathy) proposed by Wyburn-Mason.
}

Feb. 16, 1939, by Dr. D. Kendall, and the pathological material from this case was presented by the present author at a pathological meeting of the Society on May 18 of the same year.

A boiler cleaner aged 59 years was seen by me at St. Bartholomew's Hospital, London, in December, 1938, suffering from numbness of both feet, both hands, and the face. In his previous medical history the only illness of note was of a carbuncle on the neck eight years earlier. He had occasionally drunk beer, never spirits. He had not been exposed to lead or to any noxious fumes. Since about August, 1938, he had felt generally depressed but not definitely unwell. In early October, 1938 , he developed an ache in his right ear radiating into the right side of the neck. After fourteen days he noticed a numbness of the soles of both feet which advanced up the legs a little in the following three days. At this time he first noticed a numbness round his mouth and this gradually spread to involve the whole face in the course of a few days. At the same time the hands were becoming num's. The numbness of face, hands, and legs thus rapidiy developed in seven to ten days, then remaining fairly stationary. Throughout late December and all January he received thiamine by intramuscular injection. In early January he began to have intermittent tingling sensations in both hands and both feet. In this period he had intermittent stabs of pain in the inner aspect of the ankles and radiating to the knees and buttocks, and the numbness spread up the legs to the knees and up the forearms to above the elbows. On Jan. 20, 1939, he was transferred to the National Hospital, Queen Square, under the care of Dr. Gordon Holmes. He had no headaches, no disturbance of vision, no tinnitus or vertigo, and no dysphagia or dysarthria. There was no disorder of sphincter control. His appetite had been poor for the duration of his illness, but there was no deficiency in diet. He had lost about $30 \mathrm{lb}$. in weight in the previous six months. His stools had been natural and never tarry.

On admission to the National Hospital he was pale and thin but cheerful and co-operative in examination. Vision was unaffected and the optic discs of good colour. Ocular movements were unaffected, and no pupillary 
abnormality was found. There was no nystagmus. Sensation of pain was absent over the whole face and tongue, and the corneal reflexes were absent. Sensation to light touch was also absent over the whole face, and only impaired deep sensibility and temperature sense remained. The masseters and temporal muscles contracted well, as did all the facial, palatal, and lingual muscles. There was no visible muscular atrophy. The patient was, however, quite unaware of the position of his tongue. Hearing was reduced to two inches in the right ear and two feet in the left (tuning fork) with negative Rinne in the right side. The sternomastoids and trapezius contracted well.

In the upper limbs there was no loss of power of muscular contraction, and though there was a general thinness there was no atrophy. There was severe ataxia in the finger-nose test, but posture was well maintained. The limbs felt hypotonic on manipulation. He was unable to sit up without assistance, but all trunk muscles could contract. In the lower limbs there was some reduction of power of all movements of hip and knee joints, though power of movement of feet and toes appeared natural. All muscles were small, but atrophy, greater than was accountable by general cachexia, was thought to be present in all the thigh muscles of both sides. The heel-shin test revealed gross, irregular ataxia in both lower limbs. The electrical reactions of the muscles were not ascertained.

The biceps, triceps, and supinator jerks were all present on both sides but were sluggish and difficult to elicit. The knee jerks and ankle jerks were absent in both lower limbs. No abdominal reflexes were obtained. The plantar responses were both flexor.

Sensation to pain was generally impaired over the whole body. In a few patches, on the thighs and over the abdomen, a pin prick was recognized as such, whereas in the periphery of the limbs no pain sensation remained. Sensation to light touch and to temperature was grossly defective all over. Sense of passive movement was absent at all joints. Sense of vibration remained only on the clavicles, sternum, and upper dorsal spines.

Walking was possible only with assistance, and was shuffling and grossly ataxic.

On general physical examination some clubbing of the fingers was noted but no gross respiratory signs. The heart was normal, and peripheral circulation good. Blood pressure was $120 / 90 \mathrm{~mm}$. Hg. The liver edge was just palpable below the costal margin. No evidence of glossitis, or skin lesion was present. A search for evidence of malignant disease at that time was without result.

The cerebrospinal fluid was clear and colourless, with 1 cell per c.mm., the total protein $100 \mathrm{mg}$., the globulin (Pandy) positive, the colloidal gold 0001221000, and the Wassermann test negative. Examination of the blood showed $4,840,000$ erythrocytes per c.mm., hæmoglobin 92 per cent., white cells 5,600. On Feb. 17, 1939, a trace of lead was reported in the urine but it was decided that the amount was not significant. 'A differential blood count was reported as follows: leucocytes 13,400 per c.mm., polymorphs 84.5 per cent., lymphocytes 14.5 per cent., eosinophils $1^{\circ} 0$ per cent.
Soon after the clinical state reported above, on Jan. $21 \frac{\mathrm{C}}{\mathrm{D}}$ 1939 , the patient developed retention of urine for three days, following which he again voided naturally $\triangle$ Following further intensive vitamin $\mathbf{B}_{1}$ therapy there appeared to be slight improvement in sensibility to pin prick over the upper arms and thigh by Feb. 2. On Feb. 18 he developed respiratory embarrassment and was found to have impaired breathing at the base of boths lungs with a loud pleural friction at the right apex. Hen then developed signs of extensive pulmonary consolida tion and died on March 5, 1939.

ANATOMICAL FINDINGS.-The anatomical findings: were of (1) bronchial carcinoma ; (2) secondary carcinos matous metastasis to stomach; (3) mild hepatitis (4) terminal bronchopneumonia ; (5) severe degeneration of the cranial and spinal dorsal root ganglia; and (6) mild chronic polymyositis.

At post-mortem examination the following abnor malities were noted. Though the brain and spinal corces appeared normal, the sensory roots of the trigeminalnerves were greyer than the motor roots, and the spinaf dorsal roots were everywhere rather more grey than the $\vec{\omega}$ ventral roots, especially in the lumbo-sacral enlargement, where they were also congested. The ganglia on these roots appeared natural but congested.

CHEST.-There was some turbid yellowish pleurg $\angle$ fluid on the left side, and a mass of degenerating tumøुri was present, coming to the surface over the outer aspatw of the lower lobe and connected with a firmer m\&ss arising in the wall of the bronchus to the lower lobe. mass of glands was present at the hilum. Some smail patches of bronchopneumonic consolidation were present on the surface of the left lower lobe. The righ lung was unaffected.

HeArt AND AOrTa.-These were healthy.

LIVER.-The liver was shrunken and rounded, and weighed $1,700 \mathrm{~g}$. The cut surface was firm and rather yellow.

- SPLEen.-The spleen was rather large and soft, with some softened tumour tissue on its inner surface (from the wall of the stomach).

SтомасH.- On the upper margin, near the cardiac end $\overline{\overline{0}}$ but not communicating with it, was a cancerous ulceration covered on its inner surface by blackened blood. The lower few wontimetres of the œsophagus were diffusely: swollen, but not ulcerated. The stomach itself was much distended, but the pyloric end was normal, as were also the intestines.

Kidneys, Suprarenals, Bladder, and Prostate. These were healthy.

Microscopic Examination.-Sections of the lung, stomach, and liver, of various levels of the spinal cord,응 brain stem, and cerebellum, of the right sixth and seventh cervical, first and tenth dorsal, third and fourth lumbar, and first and second sacral dorsal root ganglia and both gasserian ganglia, of the sciatic, posterior tibial, and $N$ sural cutaneous nerves, and of the soleus and gastrocnemius muscles were made and stained by a variety of 0 methods. The tumour of the stomach and lung consisted $w$ of a solid mass of very elongated darkly stained nucleio

$x^{2}$


with no visible cell body except in mitotic cells. These were intersected but not broken up into alveoli by fine connective-tissue channels (Figs. 18 and 19). The cells were more elongated and less degenerated than in most bronchial carcinomas, and the connective tissue was less in evidence.

The liver showed some thickening of the connective tissue of the portal tracts, which in a few places completely enclosed small lobules. There was, however, very little degeneration of liver cells and no definite cirrhosis.

In the central nervous system the only abnormality was a very severe degeneration of the dorsal columns of the spinal cord (Fig. 3). Both the columns of Goll and of Burdach showed few remaining fibres throughout their length. There was no inflammatory reaction, and the degeneration was consistent with simple Wallerian degeneration of the central processes of the dorsal nerve roots. Occasional anterior horn cells, three or four in all, showed slight axonal reaction, but the remainder were of normal appearance. No abnormal granules were present in either Nissł or hæmatoxylin preparations. The brain stem and the cerebellar cortex showed no abnormality. The purkinje cells were unaltered. There was no change in the meninges of brain stem or spinal cord.

The dorsal nerve roots were severely degenerated. Those in the lumbo-sacral region showed only occasional myelinated fibres (Fig. 11) and, in sections stained by the Bielschowsky method, an occasional axis cylinder. In place of the absent fibres there was only the bands of Bungner with chains of Schwann nuclei characteristic of degenerated nerve. An occasional lymphocyte or fatty macrophage remained. The meningeal covering of the roots was of natural appearance. The ventral nerve roots were of natural appearance, without degeneration of fibres. Sections stained by the Weigert method, however, revealed a conspicuous widening of the nodes of Ranvier on every ventral root fibre (Fig. 10), and some were beaded for a segment between normal segments, but there were no fat droplets or cellular change. All the axis cylinders were unoven in calibre, presenting regular nodular swellings which appeared to correspond with the nodal loss of myelin of Weigert preparations.

The dorsal root ganglia were profoundly altered. In the lumbo-sacral ganglia hardly a single dorsal root cell remained (Figs. 1 and 2). In place of the missing cells small nests of darkly stained oval nuclei clustered within a capsule of pale oval connective-tissue cells (Fig. 6) were seen scattered uniformly throughout the ganglia. The outer capsule of these " residual nodules "(Nageotte) were sometimes laminated in several layers of connectivetissue cells (Fig. 6) but this was rare. The central cluster of true capsular nuclei were often in the form of a star, but sometimes more loosely arranged. A small darker rounded nucleus was rarely included. The connectivetissue stroma of the ganglia was slightly more cellular than normal. The blood vessels were of natural appearance except that the media of some of the arterioles showed some hyalin thickening. In one or two places a few lymphocytes surrounded a small venule. Lymphocytes and occasional plasma cells lay scattered through the tissue surrounding residual nodules (Figs. 2 and 6). Except for two isolated instances no pigment remained in the capsules, but in places fine granules of pigment remained in the fixed connectivetissue cells of the stroma. An occasional nerve fibre, intact in both myelin and axis cylinder stains, could be found in relation to an isolated surviving dorsal root ganglion cell. Few of such isolated nerve cells were of natural appearance. The remainder exhibited chromatolysis, swelling, and the nuclear change of cell disease (Fig. 9). The outer fibrous capsule of the ganglia was unaltered.

The cervical dorsal root ganglia were of the same appearance except that more surviving ganglion cells were found, (from two to ten in each section). Nearly all surviving cells showed the alterations described in the lumbo-sacral ganglia. The gasserian ganglion presented the same disappearance of ganglion cells, complete in the lateral two-thirds of the ganglion (Fig. 5). In the inner third many ganglion cells remained. Here, and occasionally in the cervical ganglia, some remaining nerve cells exhibited partial damage with loss of chromatin, ragged outline, and subcapsular proliferation of dendrites. Where such proliferation was occurring there was-also swelling of the capsular cells, and proliferation of the outer capsule. The appearance of a laminated outer capsule in some "residual nodules" would correspond to the death of the cell body after an earlier stage of subcapsular and capsular proliferation.

The loss of all the dorsal root fibres was in striking contrast to the compact undegenerated ventral root as it passed the ganglion, and as it merged into the peripheral spinal root (Fig. 1). As the motor fibres became spread out in the combined spinal root some irregularity of calibre was clear. Each fibre attenuated to a thin thread at the node of Ranvier (Fig. 12), and was thickened, often tortuous, in the internodal segment. The greatest thickening, sometimes an actual swelling, occurred at the Schwann nucleus in the mid-internodal region. Nevertheless, there was no fragmentation of axis cylinders or myelin in motor fibres. In one place, in one section, ventral to the first sacral ganglion, a few fibres of the ventral root were all greatly swollen as they passed a small venule near the perineurium. There was no cellular change or other evidence of inflammation. The vessels of the nerve appeared normal.

The grey ramus communicans was clearly seen and was full of non-medullated fibres (Fig. 12). Though no sympathetic ganglia were sectioned there was this evidence that sympathetic cells were not destroyed.

The peripheral nerves showed varying mixtures of intact nerve fibres of even calibre, presumably nearly all motor, and degenerated bands of Büngner (Figs. 4 and 8). A few residual globules in phagocytic cells stained with Weigert's method, but otherwise most fat globules, phagocytes, and other evidence of degeneration had disappeared, leaving only quiescent Schwann bands. The remaining axis cylinders showed the same irregularity of calibre which was evident in the motor nerve roots. In a sensory nerve (Fig. 7) no intact myelin sheaths remained. The nerves entering the muscles showed the loss of one-third to one-half of the fibres. 
The muscles were pale and thin. On section there was a considerable increase in cellularity (Fig. 13). The nuclear increase was chiefly due to the large number of muscle nuclei. The rod-shaped nuclei immediately under the sarcolemma were increased in number in every fibre, and in many there were in addition oval pale nuclei embedded in the striate substance. In some large fibres the centrally placed nuclei were arranged in long columins, and in this case they tended to a narrow, blunt-ended, shape, as if compressed. The endomysium was more than twice as cellular as normal, the increase being due to the presence of many histiocytes and occasional small lymphocytes. The histiocyte nuclei stained darkly with hæmatoxylin, with poorly developed nucleoli (seen between the muscle fibres in Figs. 13, 16, and 17). There was no change in the blood vessels, and no lymphocytic or other infiltration. The muscle fibres varied greatly in diameter, some being more than twice natural size, most being thin, and a few reduced to chains of nuclei within a membrane. This variation was irregular and haphazard. Swollen fibres had diminution or absence of cross striation and stained poorly with hæmatoxylin. Longitudinal striation was more prominent in such fibres. No vacuolation of the muscle fibres was seen. In places isolated large muscle fibres showed clumping of the sarcoplasm of one segment of the contents, but there was rarely any cellular reaction to such a mass. In the few exceptions the muscle nuclei had clumped on either side of the coagulated segment, as if the process had been very recent. No isolated hyalin masses or multinucleated aggregation were found.

With the Bielschowsky method good impregnation of large numbers of nerve endings in muscle was obtained. The intramuscular nerve plexuses were of normal appearance, and it was clear that degeneration of motor fibres had not occurred. There were many normal motor endings on normal muscle fibres, and these accounted for approximately fifty per cent. of the motor endings seen. Other axis cylinders showed, however, the same irregularity in calibre as in their more proximal course, except that the swellings were here more isolated beads, the remainder of the axis cylinder greatly attenuated. As the nerve fibre reached the motor ending of a swollen, altered, muscle fibre it became very thin, and the terminal ramification in the end plate was swollen, resembling a leaf on a thin stem (Figs. 14, 15, and 17). The nuclei of the end plate were clumped peripherally in a semicircle, but otherwise of natural appearance. This curious reversal of the relative size of nerve fibre and terminal ramification was most clear on large swollen muscle fibres. Very thin atrophic fibres showed only one or two slender axis cylinder branchings within the end plate, each ending in a leaf-shaped bulb. Just before the axis cylinder reached the end plate in such fibres a thickening was present and in a few a budding proliferation had occurred at this point (Figs. 14 and 15). On some large muscle fibres which still showed striation but having swollen and unusually obvious sarcolemmal nuclei the motor ending was greatly swollen (Fig. 16). This was interpreted as the first change in response to the process of hyalinization of muscle. Two muscle spindles were studied. . Each lacked a sensory ending, but retained motor endings with beaded processes. The intrafusal muscle fibres were unchanged.

The sympathetic nerve fibres accompanying the blook vessels in muscles were present, unchanged.

Case 2.-A retired Army Colonel, aged 71 years, was? first seen by us on Oct. 1, 1939, when he complained of unsteadiness in walking for three months. His con-0 sumption of alcohol had been high in middle life but had greatly lessened in the ten years preceding his? illness. There was no history of neuritic illness prior to the present complaint. He had suffered from mild? osteo-arthritis in the left knee for three years. In February, 1939, he had an attack of influenza, and thoughes this was considered mild he had never felt well since? Early in July he found that both legs were unsteady in walking, and about the same time noticed a feeling ofe pins and needles in the fingers and toes. Gradually ind the next three months the paræsthesia in the extremities gave place to numb, dead feeling, movement of his legse became very uncertain, and his hands clumsy and $\overrightarrow{0}$ awkward. He frequently fell if he attempted to walkwithout support. There was no affection of vision, of $\vec{\omega}$ speech or of swallowing, and no disturbance of micturition. On examination on Oct. 1 he was found to be grossly ataxic in gait, and quite unable to walko alone. There was no disorder of the cranial nerves except for some slight slurring dysarthria in speech.in There was no glossitis. In particular the pupils were of moderate size, equal, and reacted briskly to light and accommodation. There was no disturbance of facial sensation.

The power of movement in both upper and both lower limbs was excellent but unsteadily maintained. The $e^{2}$ was extreme inco-ordination, so that in the finger-nosece $\overrightarrow{0}$ test the finger would strike parts of the face or nes, $+\infty$ and in the heel-knee test he was unable to complete the movement owing to gross unsteadiness. The bulk of all muscle groups was thin, but there was no focals wasting, and no notable weakness of any single muscle.ō He was unable to keep still except in complete relaxation, which he had great difficulty in reaching.

No tendon reflexes were obtainable in biceps, triceps, $\stackrel{2}{\overrightarrow{2}}$ supinator, quadriceps, or sural triceps. The abdominal reflexes were absent, the plantar responses both flexor.

Sensation to pin prick was diminished over the upper limbs peripheral to the elbows, and over the lower limbs:below the midthigh. There was some slight hypalgesia as high as the level of the umbilicus. Over both forearms, and below the knees, there was no remaining pain sensation. Sensation to touch was greatly diminished 3 . below the elbows and below the knees. Sense of vibration was very poor but present at the knees, and 3 felt faintly in the ankles. Position sense in the hands and feet was entirely absent.

He was admitted to the National Hospital, Queen $>$ Square, and remained there until his death on Feb. 5, 1940. It is known that his blood Wassermann was N negative. The blood count on Nov. 14, showed 3,500,000 red blood cells per c.mm., Hb 70 per cent., colour index $N$ $1 \cdot 0,11,600$ white blood cells per c.mm., polymorpho- $\omega_{\tilde{W}}$ nuclears 73 per cent., lymphocytes 25 per cent., 
eosinophils 2 per cent. On Dec. 13, 1939, the blood count was 4,160,000 red blood cells per c.mm., Hb 66 per cent., colour index 0.8 , leucocytes 25,200 per c.mm., polymorphs 85 per cent., lymphocytes 13 per cent., eosinophils 2 per cent. The case record has unhappily been lost during the war years. Though he had not complained of any respiratory disorder, he was found on admission to be suffering from a persistent cough with tenacious sputum which he stated he had had for some weeks. At this time the physical signs in the chest were those of chronic bronchitis. In the next month he became more ataxic, and pain sensation was entirely lost over all four limbs, and greatly diminished over the trunk up to a vague transition over the lower costal cartilages. Sense of touch, temperature, and vibration were also gradually lost over all four limbs. Muscular power remained full, and though he was generally thin none of the muscles was truly atrophic. Two episodes of pneumonitis, with fever and consolidation at both bases were survived in the following three months, but he developed bed sores and succumbed to terminal pneumonia on Feb. 5, 1940.

Anatomical Findings.-These were : (1) bronchial carcinoma; (2) megacolon and dilated stomach; (3) severe degeneration of the spinal dorsal root ganglia ; and (4) severe polymyositis.

The findings at the post-mortem examination were as follows :

CHEsT.-The right lung was very adherent to the chest wall. Its substance was throughout firmer than normal, with much odema and slight consolidation, and at its root was a large mass of carcinoma attached to a mass of greatly enlarged adherent glands in the anterior mediastinum. A small abscess with necrotic centre and very friable walls was present in the centre of the lower lobe. The left lung was healthy.

HEART AND AORTA.-These were healthy except for some atheroma, especially in the abdominal portion.

LIVER.-The liver was normal, but displaced to the right by great enlargement of the colon and dilatation of the stomach.

SPLeEN.-The spleen was rather large and firm.

STOMACH.-The wall was of normal thickness, the mucosa atrophic, and the organ unduly large, but not to such a degree as the colon. Small intestine of usual size. The colon was enormous throughout, about 4 inches in diameter. Even the rectum was considerably larger than normal.

KIDNEYS AND SUPRARENALS.-These organs appeared to be healthy.

Microscopic Examination.-Pieces of lung, stomach, liver, kidney, spinal cord, nerve roots, sciatic, anterior and posterior tibial nerves, median and internal cutaneous nerves, gastrocnemius and soleus muscles were stained by a variety of methods. Histologically the tumour in the lungs was composed of small oval cells with darklystained nucleus and fairly well-defined small cell body (Fig. 30). Mitoses were numerous. These cells lay in irregularily shaped masses separated by thin strands of collagen, and where the cells lay against these collagen fibres some were arranged in palisades and appeared almost columnar. In other places small rings of tumour cells were seen suggesting an attempt at acinar formation, but for the most part the cells were: scattered quite irregularly. The tumour was considered by Dr. J. G. Greenfield to be an "oat-celled" bronchial carcinoma.

No abnormality was noted in the liver, stomach, or kidney.

Sections of the spinal cord at various levels showed a severe degeneration of the dorsal columns (Fig. 24), secondary to degeneration of the dorsal nerve roots, in myelin sheath stains. No disorder was found in the anterior or lateral columns, and the anterior nerve roots were of normal appearance in cross section. One or two anterior horn cells in each section showed a mild axonal type of reaction in the form of powdering of the cytoplasm and peripheral displacement of the nucleus. Such axonal changes were minimal in degree and were most evident in the lumbo-sacral region. The remaining anterior horn cells were of normal appearance. No abnormal granules were seen. There was no inflammatory reaction of the meninges, and glial changes were limited to a mild chronic change accompanying the secondary degeneration in the dorsal columns.

The dorsal nerve roots were severely degenerated (Fig. 23) with occasional persistent phagocytes containing products of myelin degeneration. Here and there a more recently degenerate fibre was represented by a line of vacuolated phagocytes with fragments of myelin. The surviving fibres showed widened nodes of Ranvier. Many finely myelinated fibres were present (Fig. 23). In axis cylinder stains these had the finely beaded appearance of regenerated fibres and could be traced back into the corresponding ganglia.

The ventral nerve roots showed no loss of fibre content, but in myelin stains the myelin sheaths were irregular, with gaps at the nodes of Ranvier in a few fibres, and vacuolation of the myelin at this point in many fibres. In axis cylinder stains considerable irregularity of calibre was noted, but not as extensive as in Case 1 .

The dorsal root ganglia showed loss of approximately 50 per cent. of nerve cells in the lumbo-sacral region, and of 30 per cent. in the first thoracic ganglion. Residual nodules, identical with those seen in Case 1, replaced the missing cells (Fig. 20). The remaining cells were in general pale and swollen, and nearly all showed intracapsular and subcapsular proliferation of dendrites (Fig. 21). One or two ganglion cells in each section were shrunken, darkly stained, and atrophic, with proliferation and swelling of the nuclei of the subcapsular cells. One such appears on the lower right side of Fig. 20. The remaining nerve fibres in the ganglion were swollen and stained darkly with axis cylinder stains, except for some finely beaded accompanying plexuses (Fig. 21). The connective-tissue stroma of the ganglia, and the vessels traversing it, were of natural appearance. A few scattered lymphocytes were seen in the connective tissue, and in three places small perivascular accumulations of lymphocytes had occurred. The outer capsules of the ganglia and periganglionic tissues were unchanged.

The first thoracic dorsal root ganglion presented numerous examples of agonal proliferation of dendrites, 
with protrusions from the cell body in later stages (Fig. 22). The final stages were represented by shrinkage of the cell body until only a stump of argentophil substance remained among the swollen capsule cells. With disappearance of such stumps the pericapsular plexus also disappeared, leaving the "residual nodule" of capsular cells.

Each ventral nerve root, where it passed the corresponding dorsal root ganglion, was robust and presented only mild irregularity of myelin sheath and axis cylinders. In the sciatic nerve there was loss of between one-half and one-third of the fibres in each bundle, and some occasional myelin debris remained. There was no inflammatory reaction or cedema of the perineurial spaces. The same changes were found in the posterior tibial (Fig. 25) and median nerves. The residual fibres often showed gaps at the nodes of Ranvier.

The muscles showed a considerable amount of proliferation of connective tissue and sarcolemmal nuclei with swelling of isolated fibres. This change was more advanced and generalized than in Case 1 (Figs. 26 and 28), and had excited a moderate histiocytic reaction.

In most areas of gastrocnemius or soleus muscles less than 20 per cent. of muscle fibres retained both cross striation and relatively normal diameter; even in these there was an increase of sarcolemmal nuclei, often in long rows. The remaining muscle fibres were mostly pale staining and swollen to twice the normal diameter, with great increase in numbers of nuclei. About ten per cent. of fibres were reduced to small chains of pyknotic nuclei with no recognizable striate or sarcoplasmic substance, as in the upper part of Fig. 28. The largest fibres in one portion of gastrocnemius appeared to have broken into discontinuous hyaline and often vacuolated masses which stained irregularly with silver (Fig. 29) and not at all with hæmatoxylin or thionin (Fig. 27). Such masses contained two types of rounded nuclei, about half of which were pyknotic, the others pale and swollen (Fig. 27). Rarely a polymorphonuclear leucocyte was seen in the centre of such a hyaline mass. At an intermediate stage of hypertrophy of muscle fibre the whole fibre exhibited metachromatic staining with thionin (as do two fibres in the lower half of Fig. 27), but otherwise the larger the fibre the less deeply it stained with thionin or hæmatoxylin. Some diffuse argentophil property was retained by the sarcoplasm even to the most degenerate stage (Fig. 29).

The earliest stage of the process appeared to be proliferation of the nuclei lying just under the sarcolemma, as in the large fibre in Fig. 28. Rows of sarcoplasmic nuclei then appear, and the muscle substance at this stage usually had lost the transverse striation and developed a homogeneous appearance as in the upper and lower fibres in Fig. 26. At this stage some fibres showed intermittent densification and swelling, as if tending to rupture into segments. The dense areas showed an accumulation of pale oval sarcoplasmic nuclei, the thinner areas leaving clumps of darkly stained smaller true sarcolemmal nuclei, as in the middle fibre in Fig. 26. Such segmented fibres then became separate hyaline masses as in Fig. 27. The more numerous other fibres which degenerated without segmentation passed through stages of phagocytosis and shrinkage, as in the upper part of Fig. 28, and residual clumps of pyknotic sarcolemmal nuclei, without visible membrane of cytoplasm, as seen at the bottom of Fig. 28, then remained as the last residue of the degenerated fibre. There was no calcification of the damaged segments.

There was a diffuse increase of fibroblasts throughouf the endomysium, and, though wandering histiocytesp lymphocytes, and plasma cells were frequent, there were no cellular accumulations or "lymphorrhages." The blood vessels were of natural appearance. The termina贲 fasciculi of motor nerves as they reached the end plates: showed no degeneration. A few preparations of moto nerve endings were made, and these showed thickening of the terminal arborization in the end plates of moder ately swollen muscle fibres. There was only a slight increase of collagenous tissue. The tendon aponeuroses? showed no change.

\section{Discussion}

The most remarkable change in the two patients presented was the severe loss of nerve cells in the $\vec{\omega}$ dorsal root ganglia, without corresponding changeg in the ventral roots. No trace remained of the majority of affected cells, their empty capsules alone. marking their previous situation. The small clumpof satellite cells which clustered in each shrunköniv capsule is the " residual nodule " noted by Nageoflew (1907) in his description of the process of necro of the nerve cells in transplanted dorsal root ganglig. Such residual nodules have been seen in the ganglia? in tabes dorsalis by a number of writers (Thomgs and Hauser, 1904 ; Marinesco and Minea, 190 $; \overrightarrow{0}$ Bielschowsky, 1908; de Castro, 1932) though the were then infrequent, for the nerve cells are rarely lost in that disease. They have also been noted in severe infective neuritis of the ascending (Landry) type by Demme (1932), Juba and Szatmári (1937), Peters and Scheid (1938). According to Nageotte (1907) the " endothelial" satellite (amphicyte) cells $\stackrel{\square}{\Rightarrow}$ multiply and erode the degenerated nerve cells in $\overrightarrow{\overrightarrow{0}}$ ganglionic grafts, but the final phagocytosis of the remnants of the cell is performed by histiocytes (" star cells" of Cajal) which penetrate the capsule : and engulf the remains of the ganglion. The final stage in our cases is consistent with such a process.

In the two cases presented here a number of $\frac{}{3}$ intermediate changes in the process of disintegration. of the ganglion cells was seen. The most common in Case 1 was an acute swelling of the ganglion cell with nuclear change and chromatolysis. In Case 2 은 a more chronic irritative change was evidenced by $\rightarrow$ swollen satellities with spiral subcapsular and capsular proliferation of dendrites. Vacuolated $\bar{N}$ cells were not seen, but ragged or "erethrized" $\sigma$ cells (de Castro, 1932) were common. The remaining cells were of both large and small types. There $\mathrm{\omega}$ was no evidence of proliferation of the satellite cells, 
which appeared to be swollen but in normal number. In the final stage the nuclei of the satellite cells stained darkly with hæmatoxylin or Nissl stains and became spindle shaped. Whether or not the residual nodule was surrounded by single or multiple concentric lamination of pale endoneurial fibroblastic nuclei appeared to depend on the presence or absence of proliferated capsular dendritic skeins at the time of ultimate disappearance of the nerve cell. Where such whorled dendritic nets surrounded a damaged but persistent nerve cell, the capsular proliferation of fibroblastic nuclei already existed in full development.

In this reaction the satellite cells behave in a manner comparable to the Schwann cells of peripheral nerve, at first swelling and deforming degenerating axoplasm, and later becoming spindle shaped with dark rod-like nuclei. The capsular cells have the staining characteristics of the peripheral cells that we have elsewhere (Denny-Brown, 1946) called "endoneural fibroblasts." In no instance in spinal or gasserian ganglia was any cell resembling the glia of the central nervous system observed.

The whole process of ganglionic degeneration presented the appearance of a primary atrophic process of the nerve cells, without inflammatory or vascular reaction. When nerve fibres had disappeared the parent cells had also vanished. Only in the second case was there any sign of abortive regeneration in the form of fine fibrils in the sensory nerve roots, and this was uneven and ineffective. In both instances the lumbo-sacral ganglia were the most heavily affected, but the disorder was widespread.

In contrast to the ganglionic changes in tabes the degeneration of the peripheral process of the ganglion cell was as severe as of the central. In both central and peripheral axis cylinder processes of the few surviving dorsal cells the changes were seen in irregularity of myelin and axis cylinder. A sensory neuronic degeneration was described in the neuritic ("polyradiculoganglionic") form of Landry's paralysis in examples of that disease reported by Demme (1932), Juba and Szatmári (1937), and Peters and Scheid (1938), but in that disease only a relatively small number of the ganglion cells were reduced to residual nodules. Further, the ganglia, and both motor and sensory nerve roots were the seat of intense inflammatory changes, which persisted for as long as four months (Marinesco and Draganescu, 1930). Motor paralysis was profound. Such inflammatory and motor changes were absent in the cases reported here. In even greater degree the condition differs from the necrotic lesion of herpes zoster.
From the physiological point of view the condition presented a unique example of deafferentation in man. The muscular nerves showed the large deficiency (from one-third to one-half) in nerve fibres shown to occur after excision of the dorsal root ganglia in animals (Sherrington, 1894). There was no evidence of the presence of efferent fibres, or of sympathetic collaterals in the human dorsal root or dorsal root ganglion, for the few residual fibres in these structures were. fully accounted for by remaining ganglion cells. The hypothesis of Kuré and his associates (1928), that certain small axons in the dorsal roots are efferent fibres, receives no support from our material.

Though degeneration of the motor nerve roots and peripheral motor apparatus had not occurred in our cases, slight histological changes of a peculiar type were present. These changes were present throughout the length of the motor nerve fibre and consisted of a thinning of the axis cylinder and loss of myelin at the node of Ranvier, with a tortuosity and swelling in the internodal segment. There were no Erzholz granules. This type of change we have shown elsewhere to be an elementary mode of reaction related to disorder of metabolism such as ischemia, and is not necessarily associated with the impairment of conduction (Denny-Brown and Brenner, 1944). The anterior horn cells were unaffected except for occasional mild axonal reaction. No abnormal pigment was found.

The muscles also presented an unusual type of change. Proliferation of sarcolemmal nuclei and increased cellularity of the connective tissue of a kind seen in chronic myositis, or rapidly progressive myopathy were found in both cases. This change was most intense in Case 2. A portion of the gastrocnemius muscle of this case showed extensive hyaline degeneration, of Zenker type, with fragmentation of swollen muscle fibres into large ovoid masses of multinucleated sarcoplasmic material. Similar masses were scattered through the remainder of the muscle. In Case 1 some of the larger muscle fibres showed clumping of the muscle substance into segments, but the change was recent, though ante-mortem. Such fragmentation suggests the possibility of the effect of physical damage such as might occur with the stretching of swollen hyalinized muscle. Its more frequent occurrence in one part of the muscle is in favour of this view. The widespread, generalized, atrophic process, passing through stages of swelling and nuclear proliferation, which led to phagocytosis and erosion, then thinning and disappearance of the contractile substance, is considered by us to be the fundamental process. The relatively slight degree of interstitial reaction, and its complete absence in the earliest 
stage (as in Case 1), indicate a primary degenerative disorder of the muscle fibre.

The signs of regeneration of muscle fibre commonly encountered in the Zenker type of degeneration of typhoid, typhus, and epidemic influenza, and consisting of multinucleated protoplasmic masses and spindles (Lorenz, 1898 ; Forbus, 1926 ; von Meyenberg, 1929) were not seen. The few multinucleated masses that were found were clusters of small very dark pyknotic nuclei without cytoplasm, lying free in the connective tissue as sole remnants of a completely destroyed fibre. Such masses appeared to be no longer viable. There was no regenerative process. The proliferative reaction of the nerve endings seen in Case 1 has been observed by us also in cases of polymyositis. The usual atrophic changes of neuritic muscular atrophy were lacking. The lymphorrhages of acute myositis were also absent, and there was a diffuse affection of muscle fibres instead of the greater degeneration at the edge of the muscular fasciculus common in that disease, which has been reviewed by Lorenz (1898), Marinesco (1910), von Meyenberg (1929), and Burton and his associates (1923). A mild eosinophilia in Case 2 recalls the similar reaction in " polymyositis."

The condition therefore, points to a diffuse degenerative process affecting primarily dorsal root ganglion cells, associated with a degeneration of striped, voluntary, muscle fibre. The slight changes in myelin and calibre of axis cylinders of motor nerve fibres was seen also in surviving dorsal root fibres. The anterior horn cells did not show any changes of the type seen in dorsal root ganglion cells. It is considered possible that the motor neurone was beginning to show a lesser degree of degenerative disorder in the form of reactive changes in the myelin. The ganglionic degeneration of the dorsal roots provides an example of a purely degenerative disease of these cells, rarely seen in man, and of special interest in contrast with the tabetic process. From the clinical point of view the progressive numbness and ataxia, without pain, reflected the ganglionic degeneration.

Degeneration of the dorsal columns of the spinal cord, of the dorsal nerve roots and peripheral nerves, but with only slight lesions of the ganglia, was found by Zimmerman and his associates $(1934,1937,1943)$ as a delayed effect in experimental deficiency in thiamine, riboflavin, and nicotinic acid in animals. In these circumstances the neurites of the sensory neurone are severely affected, and the ganglion cells rarely degenerated. The only disorder comparable to the simple ganglionic degeneration seen in our two cases is the remarkable ataxia of swine studied by Wintrobe and his colleagues $(1938,1940,1942)$.
This disorder was produced by feeding swine a basal diet consisting of crude casein, sucrose, and lard and salt mixture, plus cod-liver oil, ascorbic acid, and yeast (1940). Many dorsal root ganglion cells disappeared, leaving only residual nodules, the remainder showing shrinkage and prominent capsular cells. Irregular swelling of myelin was found in the peripheral nerves. The dorsal columns of the spinal cord were severely degenerated and in places there was patchy vacuolar change. The lumbar ganglia were more severely affected than the cervical or thoracic. In later experiments (Wintrobe and associates, 1942) various vitamin supplements were added to the diet. The ataxia and corresponding changes in the dorsal root ganglia, dorsal roots, dorsal columns, and peripheral nerves, occurred only when the supplements did not contain either calcium pantothenate or pyridoxine. If pantothenic acid were lacking a subacute inflammation of the colon was found in addition. If pyridoxine was absent epileptiform convulsions and anæmia occurred in addition to the ataxia. Neither of these disorders was present in our cases, but our Case 2 exhibited an enormous megacolon.

Follis and Wintrobe (1945) have more recently $\overrightarrow{\vec{i}} \overrightarrow{\vec{n}}$ reported that the ganglionic degeneration was found $\frac{0}{\mathrm{D}}$ w to be more prominent in further experiments on deficiency in pantothenic acid than in pyridoxine deficiency. In the latter the degeneration was thought to begin in the peripheral extremities of the nerves as much as in the ganglia. Swank and Adamso (1948) found only a difference in degree of ganglionic lesion, which was greater in pantothenic acid갈 deficiency.

We have recently reviewed (Denny-Brown, 1947) the " nutritional ataxia" encountered in prisoners of war and others after long periods of subsistence diets composed chiefly of cereals. We concluded that the ataxia in these circumstances was related to damage to the dorsal columns of the spinal cord and was not comparable to the disorder described by Wintrobe and others. The condition described here differs in many respects, notably in its neuritic symptomatology and pathology and in the absence of retrobulbar neuritis, from " nutritional ataxia." These two cases present the first clear clinical picture closely resembling experimental pantothenic acid deficiency.

The muscular changes in our cases were an unexpected finding. Wintrobe, Miller, and Lisco (1940) found "occasional hyaline and necrotic fibres" in the muscles of the thigh in five out of fourteen animals suffering from porcine ataxia. Since these investigators found similar lesions in normal animals, and in one pig fed on wheat germ oil, no conclusion was reached. On the other hand, 

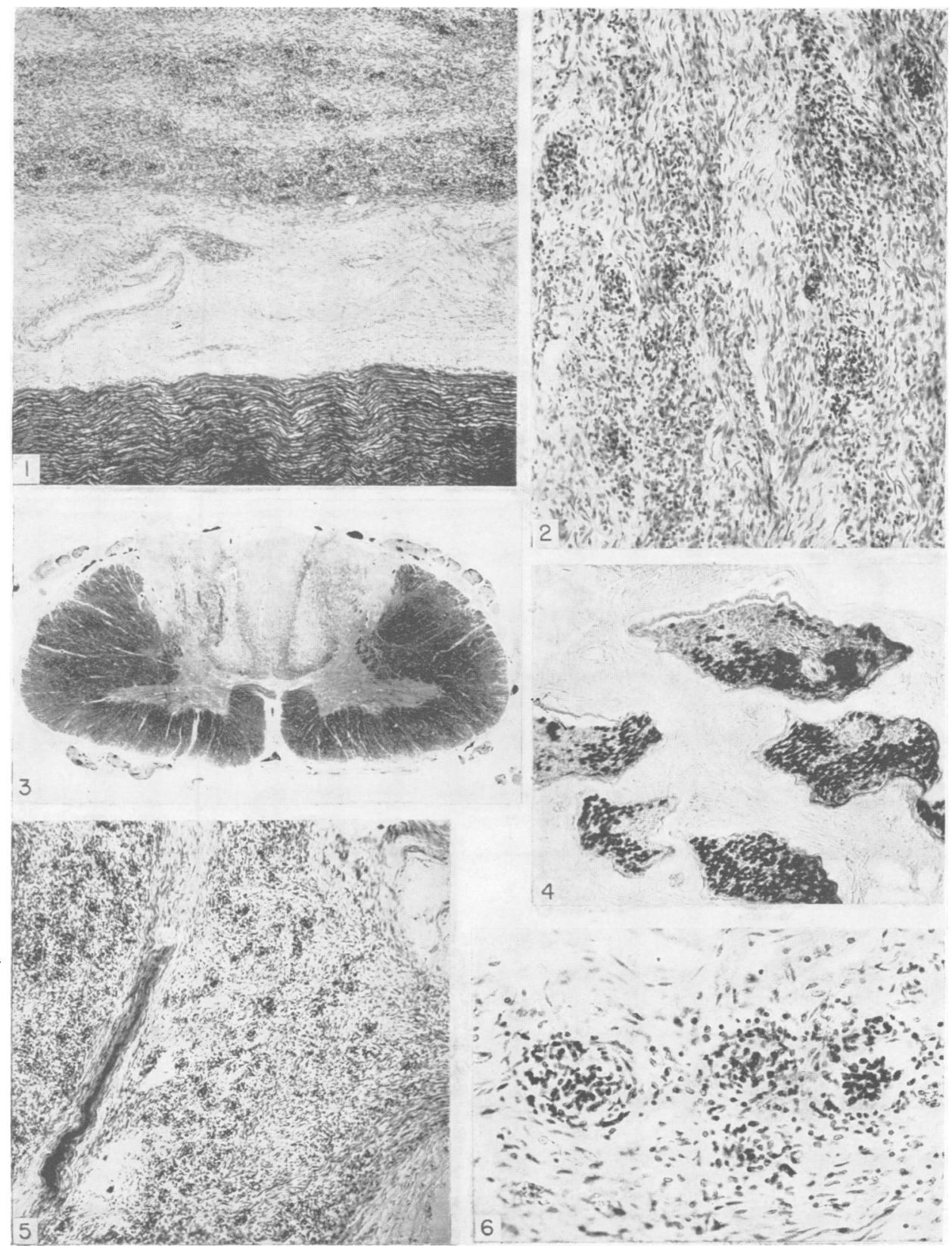

Fig. 1.-The left second sacral dorsal root ganglion of Case 1. Gros-Bielschowsky silver impregnation, counterstained with iron hæmatoxylin. The ventral border of the ganglion is shown above, devoid of nerve cells or fibres. The intact ventral nerve foot passes in the lower part of the figure, separated from the ganglion by the normal hibrous capsule.

Fig. 2.-Higher magnification of the same dorsal root ganglion to show the residual nodules, empty Schwann sheaths, and connective tissue. Iron hǣmatoxylin and Van Gieson.

Fig. 3.-Cervical spinal cord of Case 1. Weigert method.

Fig. 4.-Portion of left sciatic nerve of Case 1. Weigert method.

FIG. 5.-Left gasserian ganglion of Case 1. Gros-Bielschowsky and hæmatoxylin. A strand of intact sympathetic fibres passes vertically through the centre of the figure. This part of the ganglion is devoid of sensory cells or fibres.

Fig. 6.-Residual nodules, stained with hæmatoxylin and Van Gieson method. 

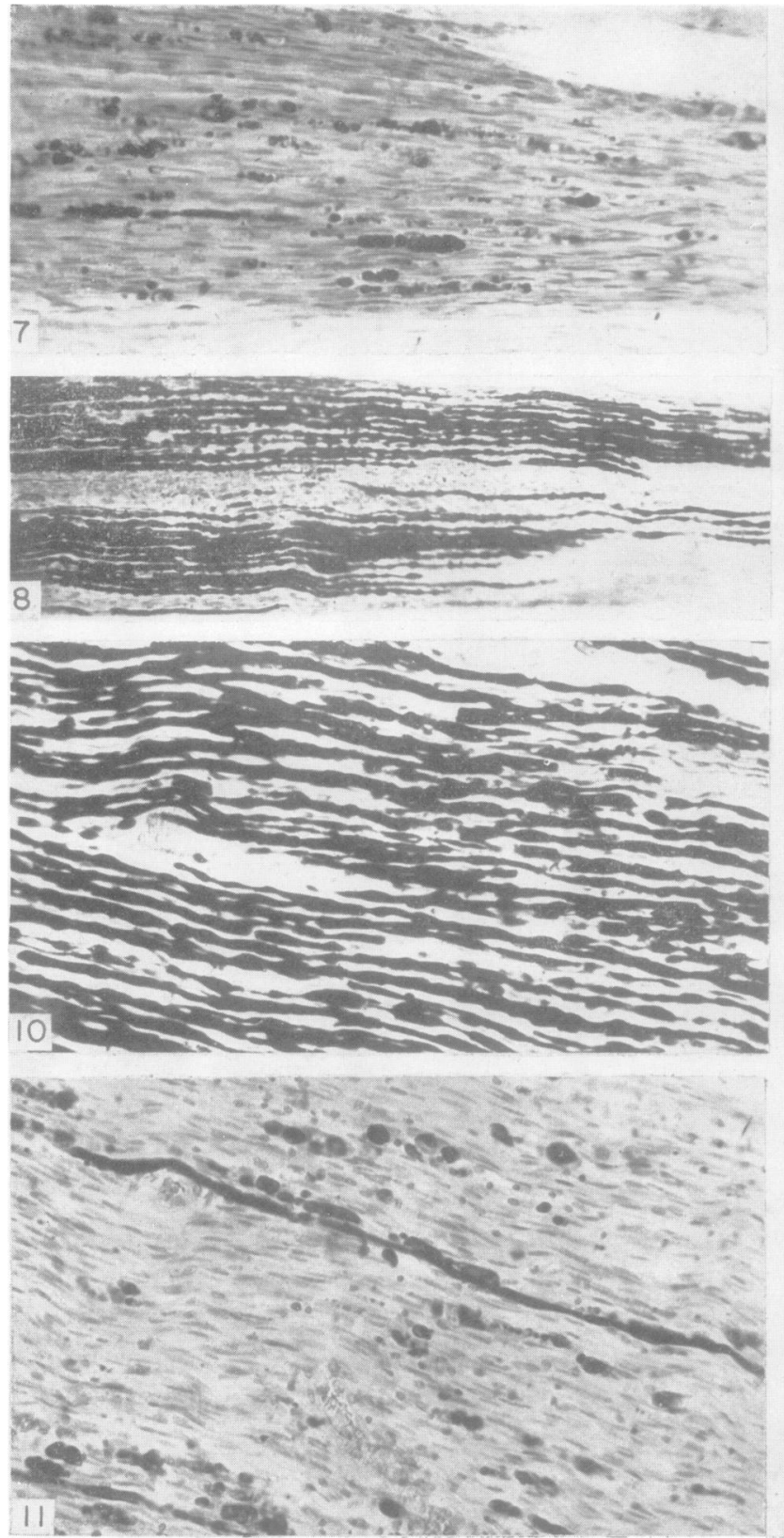

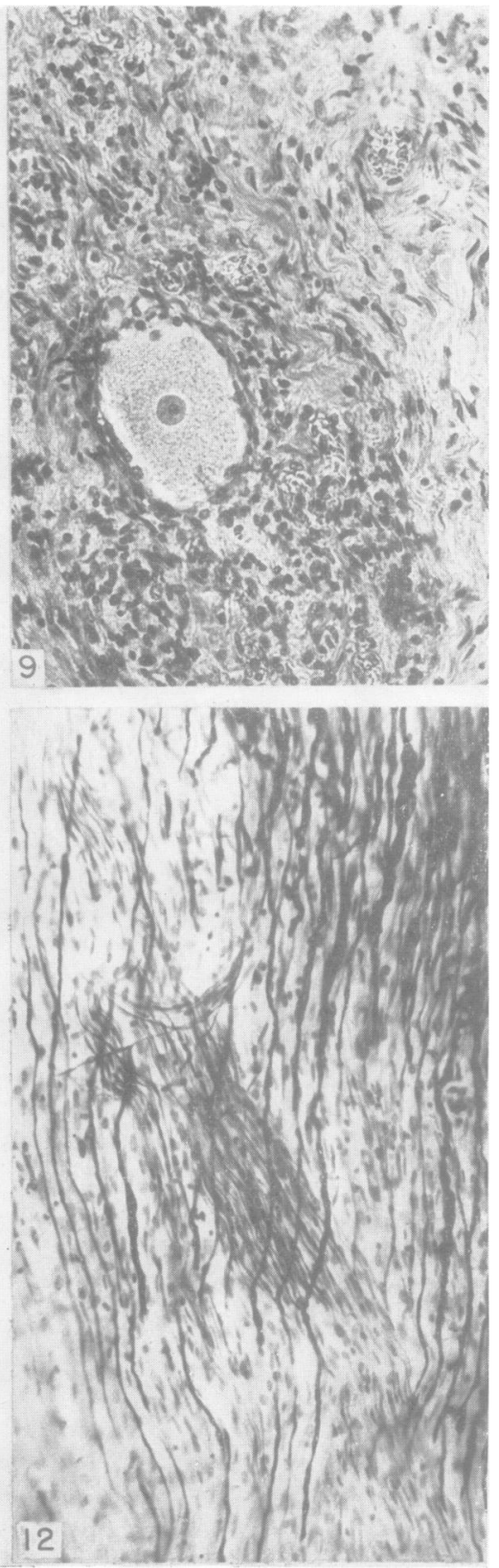

Fig. 7.-Sural cutaneous nerve. Case 1. Weigert method.

FIG. 8.-Posterior tibial nerve. Case 1. Weigert method.

FIG. 9.-A remaining dorsal root ganglion cell, first dorsal ganglion, iron hæmatoxylin and Van Gieson.

FIG. 10.-Third lumbar ventral nerve root. Case 1. Gros-Bielschowsky method.

Fig. 11.-Third lumbar dorsal nerve root. Case 1. Weigert method.

FIG. 12.-Second sacral nerve root distal to the ganglion, Case 1, to show region of junction of sensory and motor fibres with the grey ramus communicans. The intact large fibres come from the motor division. The sympathetic bundle passes obliquely across the figure. Gros-Bielschowsky method. 


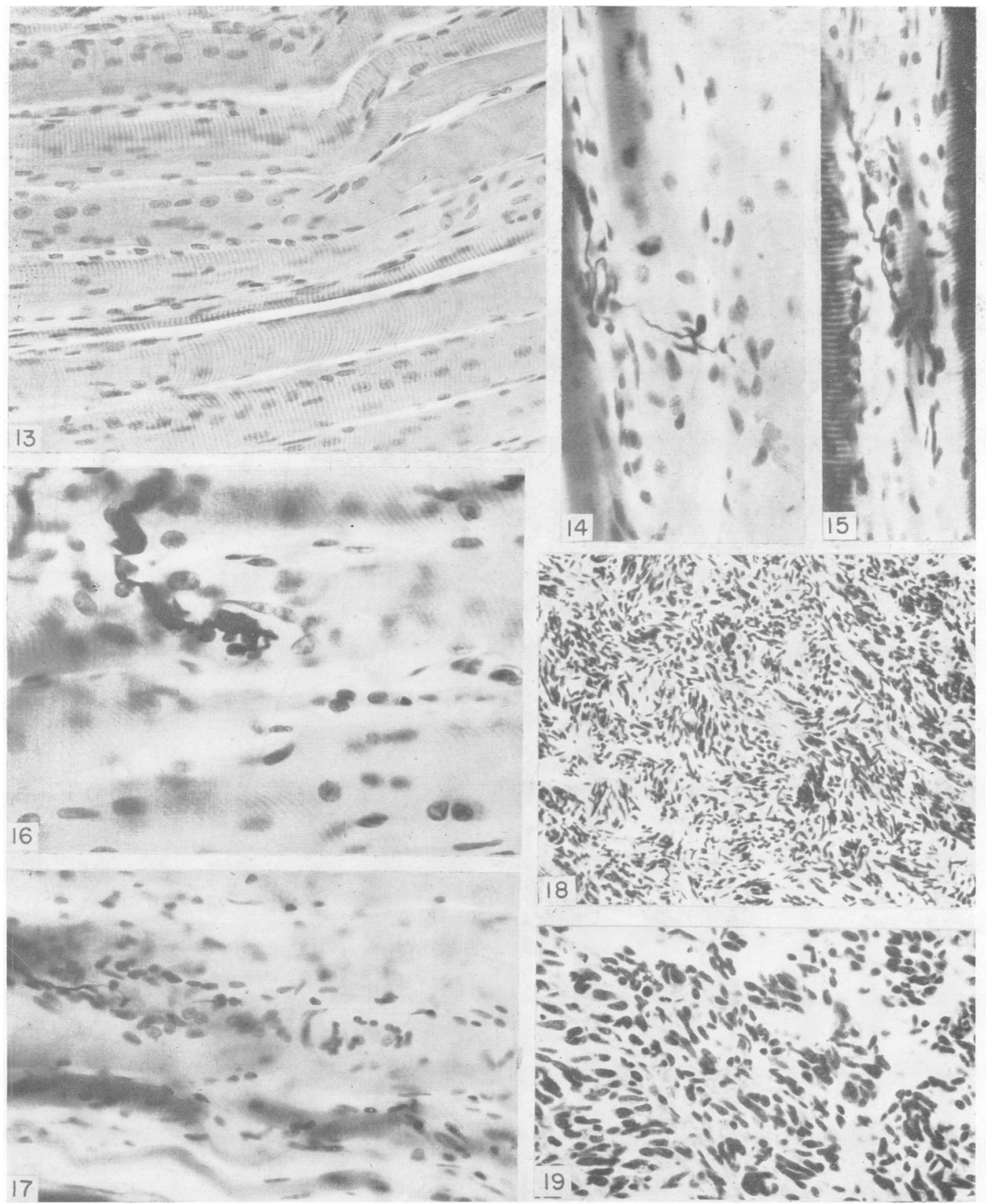

Fig. 13.-Muscle, Case 1, stained with hæmatoxylin and Van Gieson, to show the milder generalized types of change.

Fig. 14.-Motor nerve ending on a swollen hyalinized muscle fibre. Case 1. The knob just before the fibre reaches the Y-shaped terminal is a beginning of budding. Gros-Bielschowsky method.

FIG. 15.-Another motor ending, low down in the right half of the figure, with sprout passing vertically up from the middle of the figure, ending in a ball.

Fig. 16. - The early swelling of the motor termination.

FIG. 17.-To show two sprouts from the end-plate of a hyalinized muscle fibre.

Fig. 18.-Case 1, section of the tumour. Hæmatoxylin and eosin.

Fig. 19.-Higher magnification of the same tumour. 

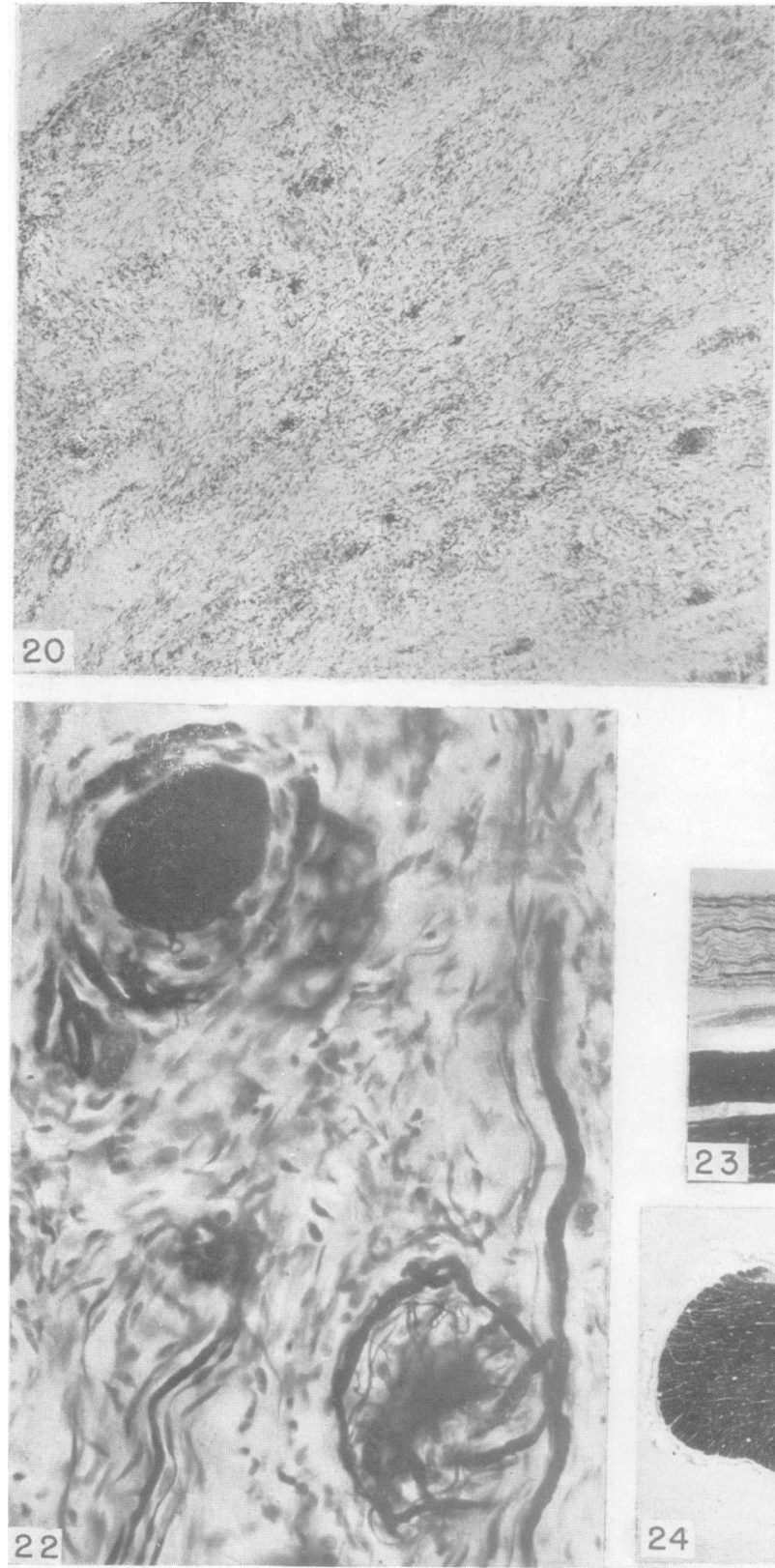
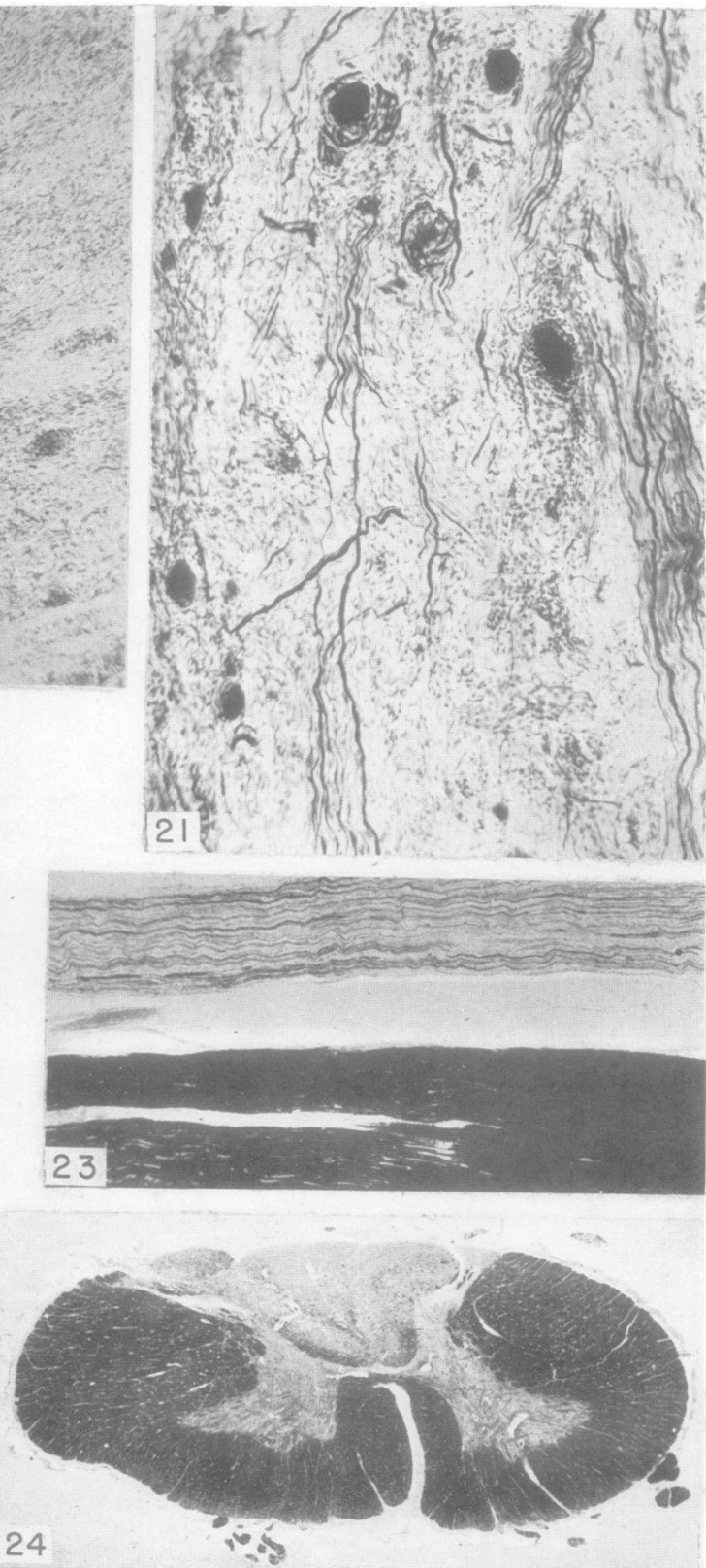

Fig. 20.-Fifth lumbar dorsal root ganglion of Case 2. Hæmatoxylin and Van Gieson. One intact ganglion cell is seen near the right border of the figure.

Fig. 21.-First thoracic dorsal root ganglion, Case 2. Gros-Bielschowsky stain. Hæmatoxylin counterstain Fig. 22.- Higher magnification of two residual ganglion cells and a residual nodule from the upper part of
Fig. 21.

Fig. 23.-Meningeal portion of fifth lumbar nerve roots, Case 2. A dorsal rootlet lies at the top of the figure, a motor rootlet below. Weigert method.

Fig. 24.-Cervical spinal cord, Case 2. Weigert. 


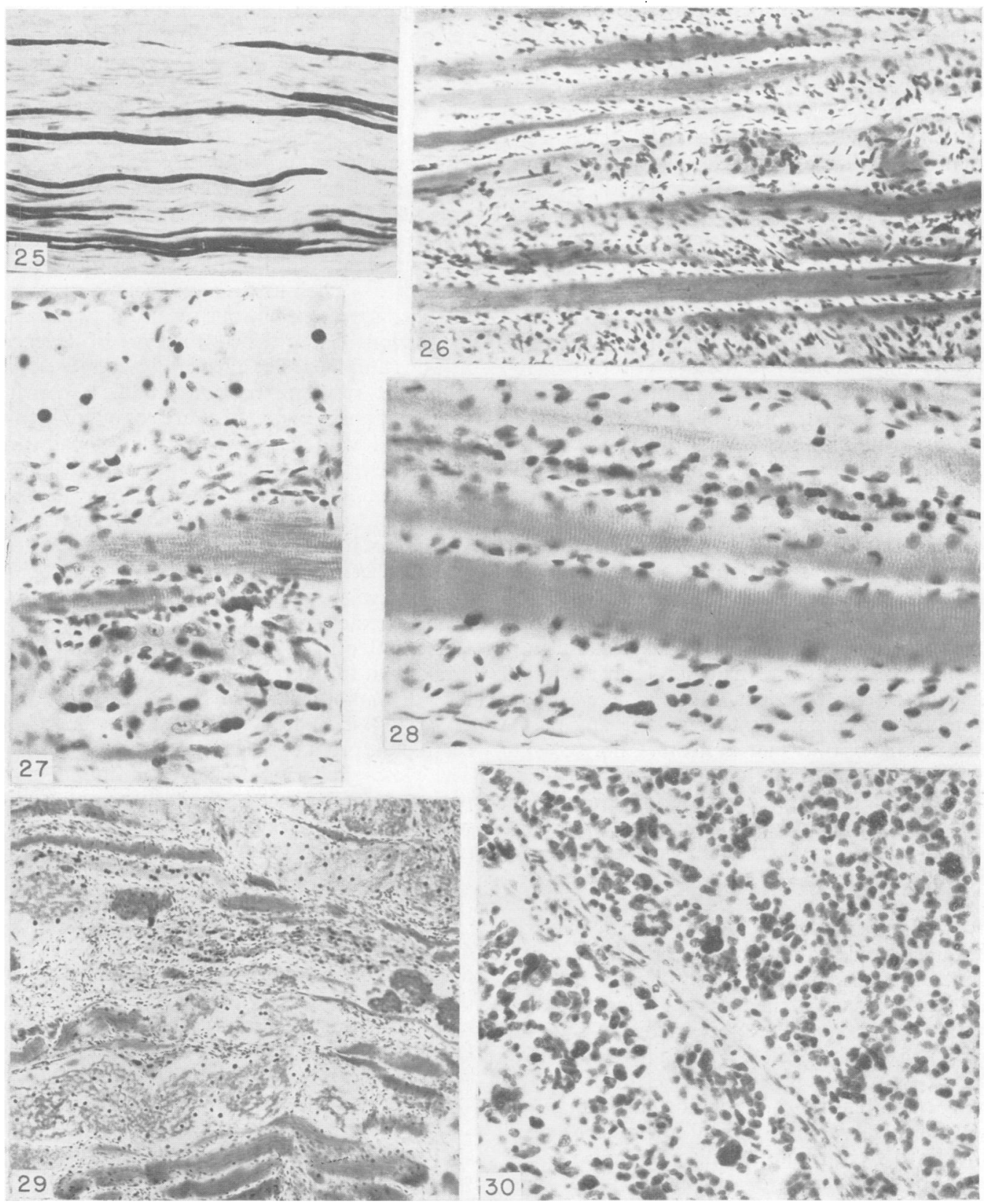

Fig. 25.-Sciatic nerve, Case 2. Gros-Bielschowsky method. Two nodal gaps are seen in the upper left corner of the figure. Corresponding Weigert preparations showed loss of myelin at the nodes.

Figs. 26, 27, 28, and 29.-Gastrocnemius muscle, Case 2, stained by Gros-Bielschowsky method and thionin.

FIG. 30.-Section of the pulmonary carcinoma, Case 2. Hæmatoxylin and eosin. 
myopathic degeneration of the hyaline or Zenker type is characteristic of the disorder produced by deficiency in vitamin E (Goettsch and Pappenheimer, 1931 ; Pappenheimer, 1939). These investigators did not find any histological change in the central nervous system. On another diet deficient in vitamin $\mathrm{E}$ similar myopathic degeneration was produced in ducklings (Pappenheimer and Goettsch, 1934), though the same diet induced an encephalomalacia in chicks (Pappenheimer. and Goettsch, 1931). Einarson and Ringsted (1938) found that rats fed on a diet deficient in vitamin $\mathbf{E}$ developed degeneration of the dorsal nerve roots and dorsal columns of the spinal cord with minimal or completely absent pathology in the dorsal root ganglia. In later stages degeneration of motor nerve roots and muscles occurred. Morgulis and others (1938), noting that rats may survive and thrive for several generations on diets deficient in vitamin $\mathrm{E}$ which induced muscular dystrophy in rabbits, are still not absolutely convinced that vitamin $\mathrm{E}$ is the sole factor leading to muscular changes.

The muscular degeneration in our two patients presents the essential histological changes described in the experimental studies of Pappenheimer. It had not progressed to such a degree as to cause more than slight weakness and had not been suspected during life in either patient. It is of interest that it is neither so chronic as to resemble any of the classical forms of muscular dystrophy, nor so acute as to be accompanied by the inflammatory reaction associated with polymyositis. In view of the prominence of sensory ganglionic degeneration the condition in our cases has more close resemblance to the pantothenic acid deficiency in swine described by Wintrobe and his associates. Since reversal of such degeneration as a result of feeding of pantothenic acid or pyridoxine, or of vitamin $\mathrm{E}$ has not been achieved, it is likely that some factor as yet undetermined is the essential defect. Indeed Mitchell (1941) reported the occurrence of a spastic ataxia in pigs fed on diets containing full supplements of yeast; it resembled that described by Wintrobe and his associates, with similar degeneration in the dorsal roots and dorsal columns. Mitchell was inclined to attribute the disorder to a mineral defect, possibly a lack of copper. "We have not found any description of such a combination of dorsal ganglionic degeneration with polymyositis in man.

The few reported examples of neuritic degeneration associated with polymyositis (" neuromyositis") by Senator and others, reviewed by Lorenz (1898) and Marinesco (1910), have exhibited minor peripheral neuritic symptoms in association with a polymyositis. One of the cases of Lorenz had loss of sensation in the right leg and foot, with hyperæsthesia in the region of the left arm and trigeminal area. There was no indication of widespread ganglionic degeneration. Though Lorenz states that ataxia is a symptom of neuromyositis we have not found it mentioned in the cases of Senator $(1888,1889)$, Lorenz $(1898)$ or Gwynn and Gordon (1910).

In both our cases bronchogenic carcinoma was present. In Case 1 a seeding of secondary deposit to the cardia of the stomach had occurred, but without interference with pyloric mechanism or structure. In neither case was anæmia or convulsive disorder observed, but our second patient exhibited megacolon. Nevertheless the type of degenerative nervous and muscular affection is entirely consistent with that resulting from metabolic disorder and present changes in man that are comparable to those associated with deficiency in pantothenic acid in swine. Dermatomyositis without ganglionic degeneration has been reported in association with malignant tumour originating in the breast, ovary, and stomach in at least seven instances (Dostrovsky and Sagher, 1946). McCombs and MacMahon (1947) have recently reported dermatomyositis with bronchogenic carcinoma. A number of substances, such as thiopanic acid and phenyl pantothenone are known to interfere with the biological conjuga-बi tion of pantothenic acid in metabolism (Woolley, 1947). It is indeed possible that bronchogenic carcinoma produces a by-product with such effect 0 The close similarity of the condition in the two patients suggests that the coincidence of carcinoma was more than a chance association. Metabolic studies on similar cases in the future are indicated.

\section{Conclusions}

Two cases of primary simple degeneration of the dorsal root ganglion cells associated with a primary degeneration of the muscles (" polymyositis") are described. Both cases presented a spreading numbness and sensory loss of the extremities, in one of the face, without pain but with severe and progressive ataxia. In both instances bronchogenic pulmonary carcinoma was present. The presence of a metabolic disorder related to the tumour cells is presumed, for the neuromuscular condition reproduced changes that have been seen in pantothenic acid and in vitamin $\mathrm{E}$ deficiency in animals.

\section{REFERENCES}

Bielschowsky, M. (1908). J. Psychol. Neurol., Lpz., $11,188$.

Burton, J. A. G., Cowan, J., and Miller, H. (1923). Quart. J. Med., 17, 103.

De Castro, F. (1932). Sensory Ganglia of the Cranial and Spinal Nerves. Normal and Pathological. Sect. III, vol. 1, in Penfield's " Cytology and Cellular Pathology of the Nervous System." New York. 
Demme, H. (1932). Dtsch. Z. Nervenheilk., 125, 1.

Denny-Brown, D. (1946). Arch. Neurol. Psychiat., Chicago, 55, 171.

-(1947). Medicine, 26, 41.

_, and Brenner, C. (1944). Arch. Neurol. Psychiat., Chicago, 51, 1.

Dostrovsky, A., and Sagher, F. (1946). Brit. J. Derm. Syph., 58, 52.

Einarson, L., and Ringsted, A. (1938). " "Effect of Chronic Vitamin 'E Deficiency on the Nervous System and the Skeletal Musculature in Adult Rats," Copenhagen.

Follis, R. H., and Wintrobe, M. M. (1945). J. exp. Med., 81, 539.

Forbus, W. D. (1926). Arch. Pathol., 2, 318, 486.

Goettsch, M., and Pappenheimer, A. M. (1931). J. exp. Med., 54, 145.

Gwynn, N. C., and Gordon, W. (1910). Lancet, 2, 226.

Juba, A., and Szatmári, A. (1937). Dtsch. Z. Nervenheilk., 142, 28.

Kendall, D. (1939). Proc. roy. Soc. Med., 32, 874.

Kuré, K., Nitta, Y., Tsuji, M., Siraisi, K., and Suyenaga, B. (1928). Quart.J. exp. Physiol., 18, 333.

Lorenz, H. (1898). “Die Muskelerkrankungen,” vol. XI, Nothnagels' "Specielle Pathologie und Therapie." Vienna.

Marinesco, G. (1910). “ Maladies des Muscles,” vol. 38, of Gilbert and Thoinot's " Nouveau Traité de Médicine et de Thérapeutique." Paris.

$\longrightarrow$, and Draganescu, S. (1930). Dtsch. Z. Nervenheilk., 112, 44.

-_, and Minea, J. (1907). J. Psychol. Neurol., 10, 182.

McCombs, R. P., and MacMahon, H. E. (1947). Med. Clin. N. Amer., 31, 1148.
Meyenburg, H. von (1929). Die quergestreifte Muskulatur, in " Handbuch der spec. path. Anatomie und Histologie." Albertini and others. Berlin, 9, 299.

Mitchell, D. (1941). Brain, 64, 165.

Morgulis, S., Wilder, V. M., and Eppstein, S. H. (1938). J. Nutrit., 16, 219.

Nageotte, J. (1907). Rev. Neurol., 15, 933.

'Pappenheimer, A. M. (1939). Amer. J. Path., 15, 179.

-

—_, and Goettsch, M. (1934). Ibid., 59, 35.

Peters, G., and Scheid, W. (1938). Z. ges. Neurol. Psychiat., 163, 367.

Senator, H. (1888). Dtsch. med. Wschr., 14, 449.

- (1889). Z. Klin. Med., 15, 61.

Sherrington, C. S. (1894). J. Physiol., 17, 211.

Swank, R. L., and Adams, R. D. (1948). J. Neuropathol. exp. Neurol. (In the press.)

Thomas, A., and Hauser, G. (1904). Nouv. Iconog. Salpêtriere, 17, 207.

Wintrobe, M. M., Miller, J. L., and Lisco, H. (1940). Bull. Johns Hopk. Hosp., 67, 377.

_- _, _- Follis, R. H., Stein, H. J., Mushatt, C., and Humphreys, S. (1942). J. Nutrit., 24, 345.

, Mitchell, D. M., and Kolb, L. C. (1938). J. exp. Med. 68, 207.

Woolley, D. W. (1947). Physiol. Rev., 27, 308.

Zimmerman, H. M. (1943). Proc. Ass. res. nerv. ment. Dis., 21, 13.

, Cowgill, G. R., Bunnell, W. W., and Dann, M. (1934). Amer. J. Physiol., 109, 440.

, - , and Fox, J. C. (1937). Arch. Neurol. Psychiat., Chicago, 37, 286.

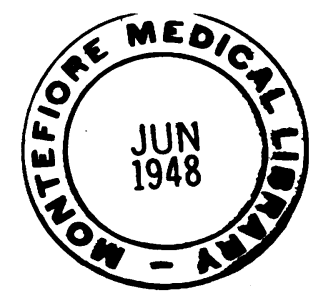

